\title{
Announcement
}

\section{Gabriella E. Molnar-Swafford, MD Pediatric PM\&R Research Fund}

The Foundation for Physical Medicine and Rehabilitation (PM\&R) - with support from Mr. Jack Swafford and pediatric physiatrists - has created a named fund to recognize and honor the worldwide contributions of Dr. Gabriella E. Molnar-Swafford as one of the founders of the field of Pediatric Rehabilitation Medicine, and to continue her work through an annual pediatric PM\&R research grant.

The purpose of the fund is to:

- Encourage young investigators in the field of pediatric PM\&R research;

- Promote the value of pediatric PM\&R research;

- Provide research support in a grossly underfunded area;

- Encourage development of PM\&R treatments to improve the lives of children with disability.

- Recognize Dr. Molnar-Swafford's leadership and innovation in the field of pediatric PM\&R.
Since starting the fund in November 2011, we have raised over $\$ 110,000$. A total of at least $\$ 750,000$ is needed to fund a $\$ 30,000$ annual grant in perpetuity.

The Gabriella E. Molnar-Swafford Pediatric PM\&R Research Grant Award has been added to the broad research support program of the Foundation for PM\&R. The first Award will be presented in November at the AAPM\&R Annual Assembly; applications for the 2013 grant cycle will be available in December.

We hope you will join in supporting this initiative to fund pediatric PM\&R research and honor Dr. MolnarSwafford's contributions in helping children with disabilities. For more information, visit the Foundation's website at www.foundationforpmr.org or contact Phyllis J. Anderson, M.A., Executive Director at panderson@foundationforpmr.org or 847-737-6062. 